\title{
edmetic
}

Revista de Educación Mediática y TIC

\section{Los entornos personales de aprendizaje}

En los últimos tiempos las TIC han cambiado de una forma exponencial los escenarios de formación; de manera que ese viejo dicho que decía que si un profesor del siglo XIX llegara a una de nuestras aulas actuales, podría desenvolverse con facilidad, al contrario de lo que podría ocurrir con un cirujano cuando entrara en un quirófano. Nuestros escenarios actuales de formación, tanto analógicos como los virtuales, son progresivamente más diferentes, y evolucionan en un corto período de tiempo, de forma que lo que hasta hace relativamente poco tiempo parecía como una tecnología que de verdad impactaría al sistema educativo en breve tiempo deja de estar presente, desaparece y sustituida por otra, que muchas veces no llega a durar mucho tiempo respecto a la que ha sustituido.

Si han existido dos tecnologías que de verdad han impactado, y cuando hablo de impactar me refiero a cambiar de verdad al sistema educativo, es decir transformar las metodologías y estrategias de enseñanza, a cambiar las formas a través de las cuales los alumnos se acercaban a construir el conocimiento, los roles que desempeñaría le profesor, o los procedimientos por los cuales los estudiantes serán evaluadores, ellos han sido el libro de texto e Internet. El resto de tecnologías sólo han producidos cambios muy específicos, y hasta podríamos decir que anecdóticos.

En la actualidad el fenómeno de la Web 2.0, está produciendo cambios significativos en cómo podemos interaccionar y desenvolvernos en la red. Por una parte, por el hecho de hacernos pasar de meros receptores, consumidores de información, a también productores de la misma, de ahí que

edmetic, 2 (1), 2013, E-ISSN: 2254-0059; pp.3-6 
se haya formado el término "proconsumer". La red ha establecido en los últimos tiempos, uno nuevo principio regulador, el de la visibilidad, somos en la red en función de que los "otros" nos perciba y vean, en cierta manera podríamos decir que la idea de Descartes de "pienso luego existo", en la red se transforma por "me ven luego existo".

Y en este principio de la visibilidad han tenido que ver bastante las redes sociales, y la potenciación de la interactividad y el intercambio como elemento básico de desarrollo e intercambio de información.

Bien, pues sobre todo esto que estamos hablando está surgiendo en los últimos años, aunque ya existía antes pero las TIC lo han amplificado lo que se denomina como "Entornos Personales de Aprendizaje", respecto a los cuales ya en su momento señalamos que podrían definirse desde dos planteamiento básicos, el tecnológico-instrumental: conjunto de herramientas de la web 2.0. que utiliza el aula para organizarse, su conocimiento, sus relaciones personales y su hábitat virtual, y pedagógico, desde la cual podría ser considerado como sistemas que ayudan a los estudiantes a tomar el control de gestión y de su propio aprendizaje, ello es de gran utilidad para que el estudiante pueda proporcionar apoyo para que fijen sus propias metas de aprendizaje; gestionar su aprendizaje; formalizar los contenidos y procesos; y comunicarse con los demás en el proceso de aprendizaje, así como lograr los objetivos de aprendizaje.

Y es precisamente sobre esta nueva "estrategia tecnológica" potenciada desde la Web 2.0, sobre la que se desarrolla el presente número monográfico de la revista "Edmetic. Revista de Educación Mediática y TIC". Y lo primero que debemos señalar es lo oportuno del tema, pues sin lugar a dudas será una tecnología que impactará en un horizonte breve a nuestras instituciones educativas, independientemente del nivel educativo en el cual se desenvuelva. Lo primero que me gustaría señalar es que en el presente número se recogen visiones sobre los PLE de diferentes profesores de distintas Universidades Españolas y Latinoamericanas, lo cual aportan una visión 
enriquecedora sobre el tema.

En el mismo se abordan diferentes problemáticas altamente relacionadas son la fundamentación de los PLE para su incorporación en los procesos de enseñanza-aprendizaje. Como la visión que se nos ofrece como elemento de fundamentación de la teoría del aprendizaje autorregulado, como la profesora Llorente de la Universidad de Sevilla nos aborda en su artículo: "Aprendizaje autorregulado y PLE".

Por otra parte nos encontramos con el artículo de las profesoras Almudena Martínez Gimeno y Luisa Torres Barzabal, de la Universidad Pablo Olavides, que podemos considerarlo como introductorio, y en él nos encontraremos desde referencias a la conceptualización de esta estrategia, como reflexiones respecto a sus posibilidades y limitaciones.

Nos gustaría destacar, por lo novedoso en las aportaciones que realizan, la propuesta que llevan a cabo los profesores de la República Ivanovnna M. Cruz Pichardo y Ángel Puentes Puente, sobre la utilización de los entornos personales de aprendizaje para la resolución de problemas en matemáticas, bajo la configuración de los e-portafolios.

Pero si novedosa es la propuesta que realizan los profesores de la República Dominicana, de actual podemos considerar el artículo de Zulma Cataldi y Fernando J. Lage de la Tecnológica Nacional de Buenos Aires, que abordan la problemática de abordar los PLE desde los dispositivos móviles. Aspectos sobre los que comienzan a desarrollarse nuevas propuestas de investigación, en la idea de favorecer las deslocalización y la flexibilidad.

Nuestras profesoras de la Universidad de Metropolitana de Venezuela, Elvira Navas y María Cecila Fonseca, reflexionan en dos artículos, sobre aspectos diferentes, una sobre las bases conceptuales en las cuales nos podemos apoyar para la utilización de los PLE como elementos para la construcción de acciones formativas permanentes, y otra, en las posibilidades que una de las herramientas de la web 2.0, como son los blog, nos ayudan a construir nuestro PLE.

edmetic, 2 (1), 2013, E-ISSN: 2254-0059; pp.3-6 
El último artículo, realizado por la profesora de la Universidad de Sevilla Margarita Rodríguez Gallego, aborda y presenta un proyecto de investigación, Dipro 2.0, que se está llevando a cabo, y que persigue la construcción de un entorno personal de aprendizaje.

Para finalizar, reconocer lo acertado de la dirección de la revista en proponer un monográfico sobre un tema de tanta actualidad, y que sin lugar a dudas lo tendrá más en el futuro, y sobre el que nos encontramos pocos referentes bibliográficos.

Julio Cabero Almenara Catedrático de Didáctica y Organización Escolar De la Universidad de Sevilla 